\title{
Effect on prices of the attributes of holiday hotels: a hedonic prices approach
}

\author{
J.M. Espinet, M. SAez, G. Coenders AND M. Fluvià
}

J.M. Espinet is with the Department of Economy, and the Research Group on Economic Analysis: Markets, Organizations, Environment and Tourism at the University of Girona, Campus Montilivi, 17071 Girona, Spain. Tel: + 34972 418032. E-mail: josepmaria.espinet@udg.es. M. Saez and G. Coenders are with the Department of Economy and the Research Group on Statistics, Applied Economics and Health (GRECS), University of Girona. M. Fluvia is with the Department of Economy, and the Research Group on Economic Analysis: Markets, Organizations, Environment and Tourism.

This article examines the effect on price of different characteristics of holiday hotels in the sun-and-beach segment. The effect on price is estimated under the hedonic function perspective by means of random effect models, known also as mixed or panel models. Some 82,000 prices were gathered between 1991 and 1998 from tour operator catalogues. The study reveals huge price differences between 4-star hotels and the rest, coupled with practically no difference between 1-star and 2-star hotels. Other attributes with a significant effect on price are town, hotel size, distance to the beach and availability of parking place. The results can assist hotel managers in shaping pricing and investment strategies.

Keywords: pricing; hedonic functions; hotels; random effect models; hierarchical models.

This article studies the effect on prices of the different characteristics or attributes of a holiday hotel in the sun-and-beach segment. Such attributes include, among others, the town in which the hotel is located, star category, size, and the services available to guests. Prices are examined from the supply perspective, assuming that the hotel market is in a monopolistic competition situation in which the hotel manager can differentiate its offer. We consider tour operators' prices, which coincide with what most tourists pay as tour operators constitute the most frequent distribution channel for tourist hotels in the sun-and-beach market segment (Espinet, 1999).

This article was partly supported by the Spanish Ministry of Science and Technology (CICYT) grant SEC-97-1465, and includes some results from the doctoral dissertation Analysis of Hotel Prices in Sourthern Costa Brava written by J. M. Espinet, supervised by M. Fluvià, and supported by a grant from the Catalan Tourism Office. 
The effect of attributes on prices can be analysed under different pricing models. In the sun-and-beach segment, hotels usually negotiate prices with tour operators as a function of the observed demand during previous years (Espinet, 1999), which is assumed to depend on hotel attributes. Even if tour operators impose the price (Taylor, 1995), the hotel attributes will still be taken into account by them. The application of cost-oriented pricing is also common in the hotel sector (Witt and Moutinho, 1994; Chias, 1996), and costs too - or at least some of them - are a function of attributes.

The value of attributes and characteristics is unobserved as they are not separately traded in any market. Only the overall prices of hotel rooms, including particular combinations of attributes, are observed. Our analysis draws upon the hedonic-prices tradition of fitting statistical models to estimate the effect of attributes on price (early theoretical developments in hedonic prices are those of Rosen, 1974; Halvorsen and Pollakowski, 1981; and Cassel and Mendelsohn, 1985. Empirical applications in the tourist sector are found in Sinclair, Clewer and Pack, 1990; Clewer, Pack and Sinclair, 1992; and Jaime-Pastor, 1999).

The product a given hotel $H$ is offering can be regarded as a set of attributes, which may consist of services (such as swimming pool, garden, television in the room), or characteristics (star category, town, year of first opening, number of rooms, etc):

$$
H_{i}=\left(q_{i 1}, q_{i 2}, q_{i 3}, \ldots, q_{i k}, \ldots, q_{i m}\right)
$$

where $i=1, n$ represents the hotel and $q_{i k}(k=1, \ldots, m)$ each of its attributes. Thus, the hedonic price function for each hotel is represented as:

$$
P_{i}=P\left(q_{i 1}, q_{i 2}, q_{i 3}, \ldots, q_{i k}, \ldots, q_{i m}\right)
$$

where the functional form of $P$ is assumed to be constant in time and across hotels, though the weight or contribution of each attribute may change.

The study of hotel-room pricing is complex because of seasonality, different price regimes (full-board, half-board, bed \& breakfast), and discounts and supplements on various grounds (additional bed for children, single room, view of the sea, additional room equipment such as air-conditioning, television, or mini-bar). In addition, three types of hotel prices are relevant in the Spanish market:

- Prices appearing in hotel guides published by official institutions such as the Spanish and Catalan Tourism Offices. These are usually maximum prices which are seldom paid.

- Prices paid when the room is reserved by the traveller directly.

- Prices appearing in the catalogues of the tour operators. As has been said, these coincide with the amount most tourists pay and are the prices considered in this study.

Studies on hotel prices are still rare in Spain. In this country, tour operators' prices are not even systematically collected by any official tourist or statistical office. A database of tour operators' catalogue prices in the area of study was gathered for the first time (Espinet, 1999) and is used in this article. The database covers an area in northern Catalonia (Spain), which is known as 'southern Costa Brava' and is very representative of sun-and-beach segment. Hedonic functions are estimated by means of random effect models. 
This article first presents the data sources and the criteria for variable selection. Next, the specification of the statistical models is outlined. Finally, the results are presented and their implications discussed.

\section{Data sources and selected variables}

Three tourist resorts are analysed: Lloret de Mar, Blanes and Tossa de Mar, which are jointly known as the 'southern Costa Brava' area (Generalitat de Catalunya, 1992). With a joint offer of 42,642 beds in 1998, they account for a large portion $(53 \%)$ of the overall hotel capacity of the Costa Brava, a tourist brand including the north-easternmost Spanish Mediterranean coast, extending for over $100 \mathrm{~km}$ along the county of Girona, belonging to the Catalan Autonomous region. Although geographically close (the two towns the furthest apart are only $18 \mathrm{~km}$ away from each other), the three towns have markedly different characteristics and are aiming at different market sub-segments (Reig-Garcia and Coenders, 2001). Lloret de Mar accounts for $72 \%$ of the capacity in the southern Costa Brava area and is considered one of the major Spanish coastal resorts. Tossa offers $17 \%$ of the beds in the area and is a smaller coastal town with a well preserved medieval quarter and town walls. Blanes offers the fewest beds (11\%), although it is the largest of the towns, and has a flourishing industrial sector and most of the area's services, including the marina and hospital (Espinet, 1999).

The database includes over 82,000 tour operator prices, daily recorded from May to October and from 1991 to 1998. The tour operator selected was Travelmar, which has the most hotels on offer and covers $62 \%$ of the rooms in the area, and from which the longest series of prices could be obtained. The number of hotels included is shown in Table 1. Prices were per person per day with a full-board arrangement (the most frequently offered) and were expressed in Spanish pesetas $(1,000 \mathrm{ESP}=6.01 \mathrm{EUR})$. The use of only one tour operator does not limit the general applicability of the results. Most hotels appear in the catalogue of more than one operator but, as the marketed product is the same, price differences between tour operators for a given hotel tend to be negligible - in fact the observed differences between operators for a given hotel are around 3\% in the high season (Espinet, 1999; Espinet, Fluvià and Coenders, 2001), which is a negligible level of variation when compared to the stochastic variation found in the statistical models in the following sections.

The examination of the tour operator catalogues and the hotel guides of the Spanish and Catalan Tourism Offices, and in-depth interviews with managers and professionals of the sector, led to the identification of 55 attributes for holiday hotels. These are displayed in Table 2. From this list, which is too large for any manageable statistical model, the most relevant were selected by giving priority to:

Table 1. Number of hotels for which price information is available each year.

\begin{tabular}{lccccccc}
\hline 1991 & 1992 & 1993 & 1994 & 1995 & 1996 & 1997 & 1998 \\
48 & 44 & 51 & 49 & 55 & 65 & 70 & 63 \\
\hline
\end{tabular}


Table 2. Complete list of attributes considered.

\begin{tabular}{ll}
\hline Town in which hotel is located & Parking place \\
Star category & Hairdresser \\
Number of rooms & Outdoor swimming pool \\
Accepts credit cards & Indoor swimming pool \\
Special access for disabled & Music or radio in the room \\
Admits pets & Conference halls \\
Air-conditioning & Sauna \\
Satellite TV & Hairdryer in the room \\
Lift & 24-hour service \\
Cafeteria & Medical care \\
Shops & Squash \\
Safe & Telephone in the room \\
Heating & TV set in the room \\
Money change & Tennis court \\
Close to town centre & Simultaneous translation \\
Discotheque & Video in the room \\
Located in a historical building & Games and recreational activities \\
Located in a picturesque building & Casino \\
Car repair & Recently renovated \\
Gymnasium & Water and wine included in full board price \\
Golf & Number of operators including it in their catalogue \\
Kindergarten & Children's swimming pool \\
Suites with living room & Restaurant \\
Garden or terrace & Close to the beach \\
Bicycle rental & Balcony in the room \\
Mini golf & View to the sea \\
Mini-bar in the room & Year of first opening \\
Park for children & \\
\hline & \\
\hline
\end{tabular}

- The opinions expressed in the in-depth interviews.

- The attributes appearing in the tour operator catalogues. Assuming rational marketing management, services appearing in catalogues should be those most valued by clients. Usually, the catalogues include information on the location of the hotel (with respect to the town centre and the beach), the characteristics of the room and the common services of the hotel.

- The ranking of important attributes of hotels in the sun-and-beach sector according to a survey carried out by the Catalan government (Generalitat de Catalunya, 1992). In the responses to that survey, the availability of a swimming pool was mentioned in $34 \%$ of cases; night activities, $17 \%$; bar, $16 \%$; sunny terrace, $14 \%$; lounge, $10 \%$; garden, $7 \%$; room service, $7 \%$; discotheque, 5\%; children's swimming pool, 5\%; side activities, $3 \%$; tennis court, $3 \%$; and television lounge, $1 \%$.

- The availability of reliable information for all hotels. This information is lacking for such services as buffet breakfast and meals, and side activities.

- Real variation across hotels. Some attributes, such as a bar, room service or a balcony, are present in nearly all the studied hotels and their effects on price cannot be estimated as they are confounded with the intercept term.

- Statistical significance in exploratory analyses carried out with cross-sectional linear regression models that were separately fitted for each date (these results can be obtained from the authors on request). 
Finally, the variables selected for the study were:

- Category. From 1 to 4 stars (H1 to H4). Dummy coded, H4 being the reference category. There were no 5-star hotels in the area. The few guesthouses available were coded as $\mathrm{H} 1$.

- ROOMS. Number of rooms.

- EQUIP. Dummy coded: 1 for hotels whose rooms are equipped with at least one of the following without price surcharge: television, air-conditioning, mini-bar.

- GARDEN. Dummy coded: 1 for hotels with garden or large terrace.

- POOL. Dummy coded: 1 for hotels with any type of outdoor swimming pool.

- SPORT. Dummy coded: 1 for hotels offering sport facilities such as tennis, squash, or mini-golf, with or without extra payment.

- BEACH . Dummy coded: 1 for hotels located right in front of the sea.

- CENTRE. Dummy coded: 1 for hotels located close to the town centre.

- RENOV. Dummy coded: 1 for hotels that have been renovated recently.

- PARKING. Dummy coded: 1 for hotels with parking place, with or without extra payment.

\section{Method}

Multilevel models, known also as random effect models, mixed models, panel models or hierarchical models, are used to estimate the hedonic functions (see, for example, Laird and Ware, 1982; Longford, 1993; Goldstein, 1995; and Diggle. Liang and Zeger, 1995). These models are well suited for hierarchical data structures such as ours, in which prices for specific dates are nested within hotels and hotels are nested within towns. These models offer the advantages of testing the hypothesis that the parameters remain constant for all hotels, towns or dates, and of estimating the variance of parameters across hotels, towns or dates when this hypothesis is rejected. One single model can be fitted to the pooled data set including all hotels and time points, and thus with increased efficiency.

The dependent variable is the monthly average of daily prices from May to October and for 1991 to 1998. This variable is log-transformed to correct heteroskedasticity. Exploratory analyses revealed a non-linear effect of hotel size that is introduced by means of a spline function (Hastie and Tibshirani, 1990) as a theory suggesting a particular functional form is lacking. In this case, splines define piece-wise linear relationships that differ in slope for each quartile of the rooms variable (minimum $=36, \mathrm{Q} 1=87, \mathrm{Q} 2=132, \mathrm{Q} 3=217$, maximum = 870). Year (dummy coded, 1991[reference category], 1992,.., 1998) and month (dummy coded: May[reference category], June,..., October) were included as additional explanatory variables to account for non-linear trend and for seasonality.

A specification search process was conducted from a general to a specific perspective. The variances of the intercept term and of the slopes of the explanatory variables across time, hotels and towns were tested by means of likelihood ratio tests and subsequently dropped if insignificant. The means of the intercept and slopes were included in the model specification throughout the whole specification search process. 
The mixed model which was finally interpreted is displayed in Equation 3:

$$
\begin{aligned}
\operatorname{Ln}(P R I C E)_{i k j}= & \beta_{0 i k}+\beta_{1 i k} H 1_{i j}+\beta_{2 i k} H 2_{i j}+\beta_{3 i k} H 3_{i j}+ \\
& \beta_{4}(\text { ROOMS })_{i j}+\beta_{5} E_{\text {QUIP }}+\beta_{6} \text { GARDEN }_{i j}+\beta_{7} \text { POOL }_{i j}+ \\
& \beta_{8} \text { SPORT }_{i j}+\beta_{9} \text { BEACH }_{i}+\beta_{10} \text { CENTRE }_{i}+\beta_{11} \text { RENOV }_{i j}+ \\
& \beta_{12}\left(\text { PARKING }_{i j}+\sum_{m=13}^{19} \beta_{m} \text { YEAR }_{j}+\sum_{m=20}^{24} \beta_{m} \text { MONTH }_{j}+u_{i j k}\right.
\end{aligned}
$$

where the $i$ subscript identifies the hotel $(i=1 \ldots 85), k$ the town (Lloret, Blanes and Tossa), and $j$ the period (May 1991, June 1991, ..., October 1998). Note that time-invariant predictors, such as closeness to the centre and the beach, have only the two first subscripts. $u_{i j k}$ is a random error term, independent and identically distributed with zero expectation and constant variance.

The model has a three-level hierarchical structure. The town variable is the top-level random factor. There is no reference group, but the effects are expressed with respect to the mean. The hotel is also specified as a random factor, nested within the town. This allows random effects to interact with town. Prices for each date are the observations nested within each hotel. The model includes both fixed $\left(\beta_{m}\right)$ and random $\left(\beta_{m i k}\right)$ effects. The former do not vary across hotels and towns. The latter include the intercept term and the slopes for $\mathrm{H} 1$ and $\mathrm{H} 2$ which were found to vary significantly across hotels and towns. The formulation of the random effects is shown in Equations 4 to 6 :

Constant term: $\beta_{0 i k}=\beta_{0}+\beta_{0 k}+v_{0 i k}$

$H 1: \beta_{1 i k}=\beta_{1}+\beta_{1 k}+v_{1 i k}$

H2: $\beta_{2 i k}=\beta_{2}+\beta_{2 k}+v_{2 i k}$

where $\beta_{0}, \beta_{1}$ and $\beta_{2}$ are the average effects for all hotels; $\beta_{0 k}, \beta_{1 k}$ and $\beta_{2 k}$ are the average effects for all hotels in the kth town; and $\beta_{0 i k}, \beta_{1 k i}$, and $\beta_{2 i k}$ are the effects for the $i$ th hotel in the kth town. The $v_{i k}$ terms represent betweenhotel within-town variation in the effects and are assumed to follow a normal distribution with zero expectation and standard deviations $\sigma\left(v_{0 i k}\right), \sigma\left(v_{1 i k}\right)$ and $\sigma\left(v_{2 i k}\right)$. These standard deviations show the size of the differences in the effects for different hotels in a given town. The extreme case of a fixed effect would correspond to a standard deviation equal to zero.

The model was estimated by restricted maximum likelihood (REML) (Patterson and Thompson, 1971), and passed the usual diagnostics for homoskedasticity and absence of outliers. The S-Plus 2000 program (Mathsoft Inc, 1999) was used.

\section{Results}

\section{Descriptive analysis}

One of the most relevant characteristics of a hotel to price is star category. Figure 1 shows the time series of average prices in the studied area for the categories of one to four stars.

Figure 1 clearly shows that the greatest differences in price occur for 4-star hotels, while those with 1 and 2 stars hardly vary. A mild growing trend and 


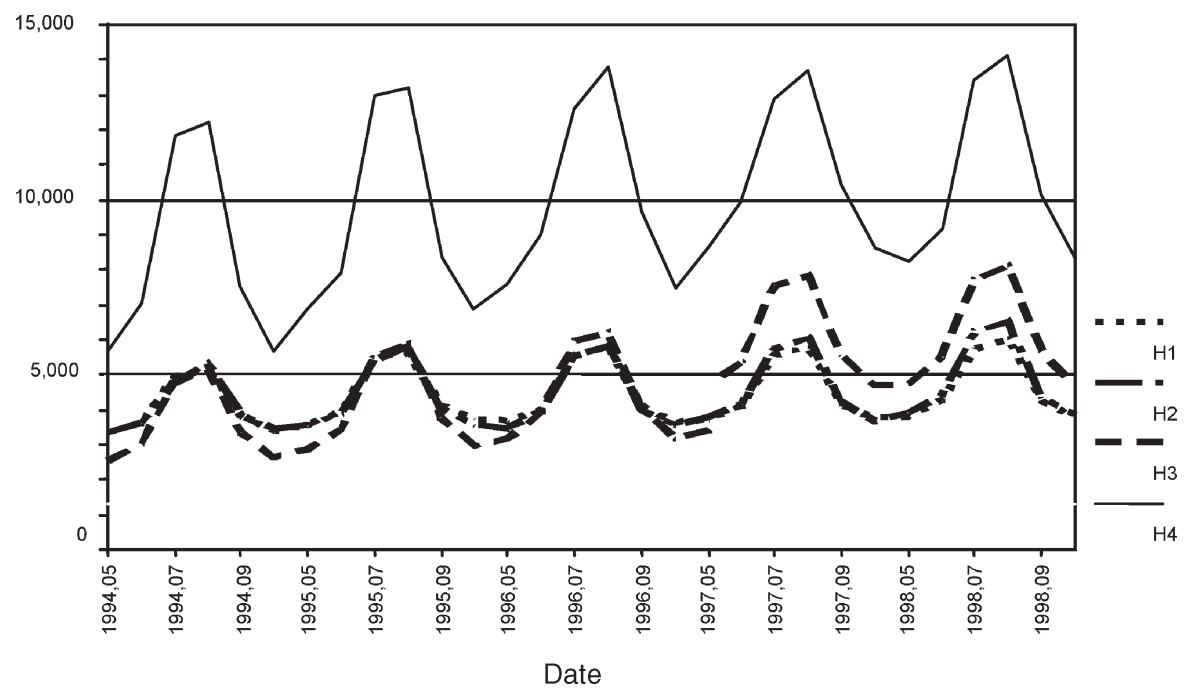

Figure 1. Average prices by star category, monthly, 1991-98.

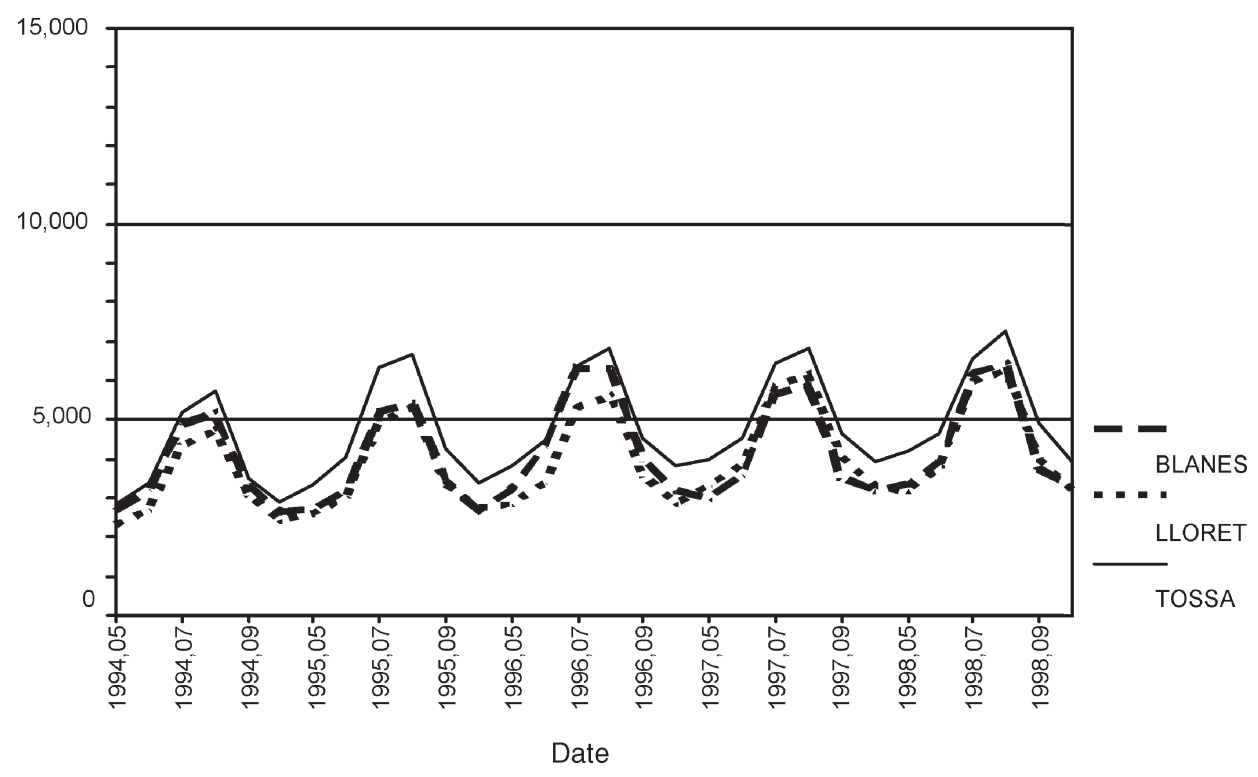

Figure 2. Average prices by town location, monthly, 1991-98.

a pronounced and very regular seasonal pattern also emerge. The peak months are August and, secondly, July.

Given the marked differences among the towns under study, the town in which the hotel is situated is another potentially very relevant variable. Figure 2 presents the average price time series for the three towns and shows that Tossa is the most expensive, while differences between Blanes and Lloret are comparatively minor.

However, these average prices can constitute a poor representation of the 
Table 3. Means and standard deviations of prices: breakdown by star category and town.

\begin{tabular}{llrrrrrrr}
\hline \multirow{5}{*}{ Mean } & H1 & H2 & H3 & H4 & Tossa & Lloret & Blanes \\
& & & & & & & & \\
& May & 2,188 & 2,198 & 2,914 & 7353 & 3,337 & 2,682 & 2,796 \\
& June & 2,564 & 2,590 & 3,500 & 8556 & 3,999 & 3,145 & 3,398 \\
& July & 4,008 & 4,121 & 5,490 & 12,368 & 5,988 & 4,981 & 5,345 \\
& August & 4,226 & 4,440 & 5,822 & 13,102 & 6,415 & 5,303 & 5,524 \\
& September & 2,696 & 2,703 & 3,765 & 9,308 & 4,183 & 3,432 & 3,423 \\
& October & 2,246 & 2,241 & 3,019 & 7,588 & 3,397 & 2,818 & 2,788 \\
\multirow{5}{*}{ Standard deviation } & Pooled & 3,045 & 3,075 & 4,104 & 9,745 & 4,597 & 3,750 & 3,911 \\
& May & 448 & 337 & 833 & 1,405 & 1,581 & 963 & 735 \\
& June & 522 & 411 & 1,012 & 1,439 & 1,735 & 1,126 & 1,040 \\
& July & 638 & 678 & 1,180 & 1,769 & 2,519 & 1,376 & 1,373 \\
& August & 722 & 627 & 1,210 & 1,660 & 2,601 & 1,435 & 1,430 \\
& September & 487 & 391 & 941 & 1,265 & 1,874 & 1,171 & 847 \\
& October & 470 & 295 & 766 & 1,182 & 1,541 & 963 & 714 \\
& Pooled & 995 & 1,017 & 1,529 & 2,665 & 2,361 & 1,577 & 1,555 \\
\hline
\end{tabular}

actual prices paid, as we found a high level of dispersion. Table 3 shows both the means and standard deviations of prices within each combination of period and category and of period and location. The high values of the standard deviations when compared to the means suggest that these two variables are insufficient to explain the actual variability in prices. In addition, Figures 1 and 2 can be misleading, as the patterns can be confounded by other variables that tend to be associated with town and category. The fit of econometric models in the next section will incorporate additional predictors and isolate their individual effects.

\section{Random effect model}

The estimates of the constant part of the coefficients in the random effect model are displayed in Table 4. All coefficients have been exponentially transformed (that is, $e^{\hat{\beta}}$ is shown and not $\hat{\beta}$ ). Thus, if 1 is subtracted from all coefficients, the result can be interpreted as a percentage change, except for the constant term. This percentage is interpreted with respect to a hotel in the reference category or without the specified attribute (dummy variables) or for each quartile increase with respect to a hotel of the minimum (36 rooms) size (rooms variable).

The coefficients can then be interpreted as follows.:

- The average intercept term (ESP 4,811 = EUR 28.91) represents the average price for the three towns of a 4-star hotel with none of the specified attributes and with a number of rooms equal to the minimum (36 rooms) in May 1991.

- Compared to the reference 4-star hotels, prices are much lower for all categories: $64 \%$ lower for 1 -star $\left(e^{\hat{\beta}}-1=0.361-1=-0.639\right), 61 \%$ lower for 2 -star, and $50 \%$ lower for 3-star hotels. The minor differences between 1-star and 2-star hotels can be related to the fact that the legal requirements for both categories are nearly identical (Espinet, 1999). 


\begin{tabular}{|c|c|}
\hline Variable & Coefficient $(*)$ \\
\hline II & Intercept 4,811 \\
\hline H1 & 0.361 \\
\hline $\mathrm{H} 2$ & 0.392 \\
\hline $\mathrm{H} 3$ & 0.500 \\
\hline ROOMS, Q1 & 0.963 (ns) \\
\hline ROOMS, Q2 & 1.000 (ns) \\
\hline ROOMS, Q3 & 0.692 \\
\hline ROOMS, Q4 & 0.806 (ns) \\
\hline EQUIP & 1.002 (ns) \\
\hline GARDEN & 1.045 (ns) \\
\hline POOL & 0.972 (ns) \\
\hline SPORT & 1.085 (ns) \\
\hline $\mathrm{BEACH}$ & 1.194 \\
\hline CENTRE & 1.038 (ns) \\
\hline RENOV & $0.974(\mathrm{~ns})$ \\
\hline PARKING & 1.085 \\
\hline 1992 & 1.114 \\
\hline 1993 & 1.099 \\
\hline 1994 & 1.091 \\
\hline 1995 & 1.230 \\
\hline 1996 & 1.272 \\
\hline 1997 & 1.330 \\
\hline 1998 & 1.390 \\
\hline JUNE & 1.193 \\
\hline JULY & 1.889 \\
\hline AUGUST & 2.010 \\
\hline SEPTEMBER & 1.282 \\
\hline OCTOBER & 1.026 \\
\hline
\end{tabular}

Note: $(*)$ Estimate for fixed effects. Estimate of mean effect for random effects. Ns $=$ non-significant at $5 \%$.

- An increase in the hotel capacity tends to be associated with a decrease in price, although only significantly so in the third quartile (between 123 and 217 rooms). The spline function relating price to size resulting from the coefficients in Table 4 is represented in Figure 3.

- Hotels located in front of the beach appear to be more expensive (by 19.4\%), while closeness to the town centre has no significant effect.

- As regards hotel services, availability of parking place increases prices by $8.5 \%$. Recent renovation, special room equipment, availability of garden, swimming pool or sporting facilities have no significant effect on price. In the swimming pool case, this lack of significance can be attributed to the fact that few hotels in the sample were lacking them.

- The effect of the year shows a non-linear trend. The year variable may act as a proxy for demand; in fact, in the studied area it can be observed that price increases tend to parallel demand increases with a certain lag (Espinet, 1999). The price increase in 1992 attributed to the Olympic Games taking place in nearby Barcelona was too high and resulted in a decrease of demand. 


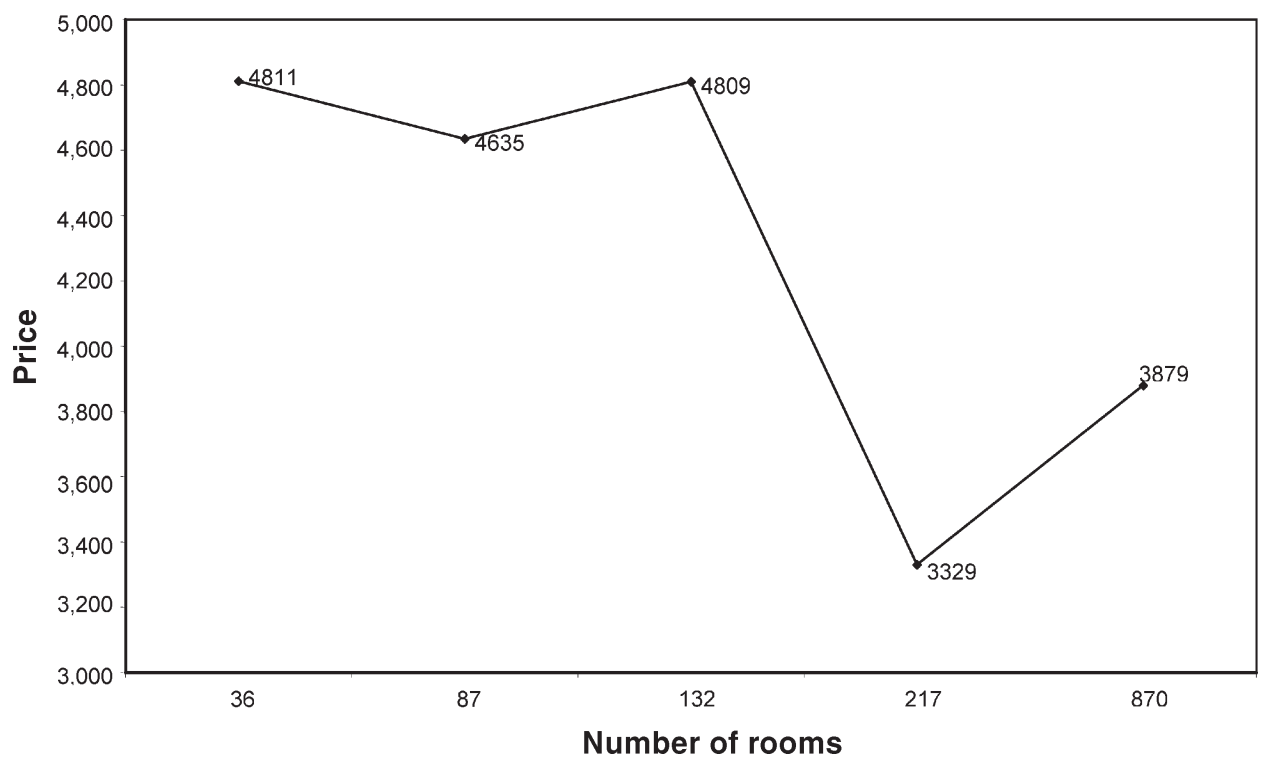

Figure 3. Relationship between price and hotel size (number of rooms).

Then prices decreased until 1994, with a break point occurring in 1995, and regular increases being observed since.

- Seasonal variation follows the expected pattern, with peaks in August and to a lesser extent in July.

The estimates of random effects are displayed in Table 5. Regarding variation in the intercept term, substantial differences can be found both across towns and within towns. Prices in Lloret tend to be $1.7 \%$ below average, in Tossa 9\% above average and in Blanes $6.7 \%$ below average. The standard deviation of 0.152 shows the variation in the intercept term within a town. If we take $+/-$ two standard deviations, we expect prices to vary at most $+/-30.4 \%$ around the mean intercept term of a given town. The residual standard deviation of the model is lower at 0.082 , showing that de-seasonalized and de-trended price differences within a given hotel across time are much lower than contemporaneous differences across hotels. It is then suggested that pricing policies differ across hotels but are consistently applied in time.

As regards between-town random effects related to category, only Lloret deviates from the average effect of hotel category and it does so only for 1-star hotels. However, within towns, the effect of category on price differs markedly between hotels.

Table 5. Significant random effects: within-town means and standard deviations of effects.

\begin{tabular}{lcccc}
\hline Variable & Lloret & Tossa & Blanes & Standard Deviation \\
Intercept & 0.983 & 1.090 & 0.933 & 0.152 \\
H1 & 1.058 & & 0.997 & 0.192 \\
H2 & 1.011 & 0.981 & 1.008 & 0.165 \\
\hline
\end{tabular}


An earlier study in the Spanish context (Jaime-Pastor, 1999) employs a substantially different methodology. To begin with, Jaime Pastor uses linear regression models. As regards prices, Jaime-Pastor uses prices from the Spanish Tourism Office, which on average are $25 \%$ above what the client actually pays to tour operators, though this percentage varies across hotels and seasons (Espinet, 1999). Instead of separately estimating the contribution of each attribute on price, Jaime-Pastor uses aggregated quantitative indexes of hotel attributes drawn up by a pool of experts. The author also treats category as a quantitative variable and assumes it to have a linear effect on price, which has been shown here not to be tenable: 1-star and 2-star hotels are barely differentiated regarding price, 1 while 3 -star hotels are about $50 \%$ cheaper than 4star hotels. Not surprisingly, Jaime-Pastor finds the current star category system to be appropriate for price differentiation in Spain. On the contrary, we must rather conclude that this system is barely useful in providing tourists with reasonable quality and price signals.

\section{Discussion}

This article has identified some variables that affect the price paid by tourists in the sun-and-beach segment, for which the major motivations of tourists are basically the same worldwide. Spain, the main destination of sun-and-beach tourists in the world, can be considered to be a typical case of this segment, and thus we hope that the results provide some hints that are useful beyond Spanish borders. The maturity stage reached by the hotel sector in sun-andbeach destinations makes differentiation a suitable strategy to adapt to customer needs and create value. The attributes or characteristics that allow hotels to increase price can also be seen as attributes that contribute to the differentiation of their offer.

The use of hedonic functions has allowed us to quantify the effect of each of the significant variables (town, star category, distance to the beach, number of rooms, and availability of parking place) on price. Thus hotel managers can make economic estimates of the impact of decisions concerning changes in these variables. This should make the results very useful to hotel managers and to a lesser extent to tour operators and public authorities.

As regards hotels, the decisions concerning some of the significant variables (town and distance to the beach) are made only once, when the hotel is built, while those concerning the other variables (star category, number of rooms and parking place) can be changed, but not without incurring considerable costs. The results are thus particularly useful to hotel chains facing new investment decisions.

To begin with, a decision has to be made on where to locate the hotel. Each tourist destination seems to have a distinct image, and this is supported by the fact that tourists often choose the destination first and then the hotel. Price differences as high as $17 \%$ between towns are possible, even within small regions. These differences have to be weighed against differences in land costs. Furthermore, hotels in front of the beach have greater expected revenues. However, as there is usually less free land at the beach front, it is more expensive. Hotel managers must again weigh the additional land costs against the additional expected revenues. 
Another important decision is hotel size. Larger size provides economies of scale but also seems to result in lower revenues per room - though evidence for this relationship could be found only in the intermediate size range, which suggests some form of S-curve. Our exploratory analyses with linear regressions - not included here - showed prices to be sensitive to hotel size especially during the low season.

Star category also affects both costs and revenues. Differences in revenue are substantial when the category shifts from 3 to 4 stars. The sector seems to be aware of this, as most new hotels in the area belong to the 4-star category, and some of the old 3-star ones are undergoing refurbishment in order to attain the higher category. The share of 4-star hotels in the whole Costa Brava area has increased consistently in recent years.

Another key variable is the availability of parking space, which also affects revenues and costs (at least opportunity costs, as the space devoted to parking could be devoted to other facilities).

Tour operators can also benefit from the results of this study, as it not only provides a guide to their pricing policies, but also can assist them to determine an appropriate range of offers that fits with the wishes of their customers in providing attributes with high added value.

Finally, the fact that the town in which the hotel is situated is one of the differentiating variables makes it clear that public authorities (mainly local and regional) can play an important role, for example by preserving the town's image through appropriate public service provision, and environmental and communication policies. The results can also guide urban planning in the direction of making land close to the beach available for hotel development rather than for other uses.

We are currently working to extend the research to other tourist areas in Spain, which will eventually enable us to analyse the reasons why some towns are more expensive than others by means of meta-analysis techniques. After that, we can attempt to include data from other countries with important sunand-beach destinations in order to assess formally the extent to which the results can be generalized.

\section{References}

Cassel, E., and Mendelsohn, R. (1985), 'The choice of functional forms for hedonic price equations: comment', Journal of Urban Economics, Vol 18, pp 135-142.

Chias, J. (1996), 'Existe o no una estrategia de precios en el turismo español?' ['Is there a pricing strategy in Spanish tourism?'], Editur, No 1894, pp 11-15.

Clewer, A., Pack, A., and Sinclair, T. (1992), 'Price competitiveness and inclusive tourism holidays in European cities', in P.Jonson and B.Thomas, eds, Choice and Demand in Tourism, Mansell, London, pp 123-144.

Diggle, P.J., Liang, K.Y., and Zeger, S.L . (1995), Analysis of Longitudinal Data, Oxford University Press, New York.

Espinet, J.M. (1999), 'Anàlisi dels Preus al Sector Hoteler de la Costa Brava Sud' ['Analysis of Hotel Prices in Southern Costa Brava'], unpublished doctoral dissertation, University of Girona.

Espinet, J.M., Fluvià, M., and Coenders, G. (2001), 'Competencia en precios entre operadores turísticos españoles' ['Price competition among Spanish tour operators'], Estudios Turísticos, No 147, pp 103-119.

Generalitat de Catalunya (1992), Reforçament de l'Avantatge Competitiu del Sector Turístic a Catalunya 
[Reinforcing Competitive Advantage in Catalonia's Tourist Sector], Departament d'Indústria, Comerç i Turisme, Barcelona.

Goldstein,H. (1995), Multilevel Statistical Models, Halsted Press, New York.

Halvorsen, R., and Pollakowski, H.O. (1981), 'Choice of functional form for hedonic price equations', Journal of Urban Economics, Vol 10, No 1, pp 37-49.

Hastie, T., and Tibshirani, R. (1990), Generalized Additive Models, Chapman and Hall, London.

Laird, N.M., and Ware, J.H. (1982), 'Random effects models for longitudinal data', Biometrics, Vol 38, pp 963-974.

Longford, N.T. (1993), Random Coefficient Models, Oxford University Press, New York.

Jaime-Pastor, V. (1999), 'Un análisis de los precios hoteleros empleando funciones hedónicas [Análisis of hotel prices using hedonic functions]', Estudios Turísticos, No, 139, pp 65-87.

Mathsoft, Inc (1999), S-PLUS 2000 User's Guide, Data Analysis Products Division, Mathsoft, Seattle, WA.

Patterson, H.D., and Thompson, R. (1971), 'Recovery of inter-block information when block sizes are unequal', Biometrika, Vol 58, pp 545-554.

Reig-Garcia, C., and Coenders, G. (2002), 'Segmentación del mercado turístico según las perferencias ambientales' ['Segmentation of the tourist market according to environmental preferences'], Cuadernos de Turismo, Vol 9, pp 109-121.

Rosen, S. (1974), 'Hedonic Prices and implicit markets: product differentiation in pure competition', Journal of Political Economy, Vol 82, No 1, pp 34-55.

Sinclair, M.T., Clewer, A., and Pack, A. (1990), 'Hedonic prices and the marketing of package holidays: the case of tourism resorts in Malaga', in G. Ashworth and B.Goodall, eds, Marketing of Tourism Places, Routledge, London, pp 85-103.

Taylor, P. (1995), 'Measuring changes in the relative competitiveness of package tour destinations', Tourism Economics, Vol 1, No 2, pp 169-182.

Witt, S.F., and Moutinho, J. (1994), Tourism Marketing and Management Handbook, Prentice Hall, Upper Saddle River, NJ. 
